\title{
Behavioral rhythms of hydrocarbon seep fauna in relation to internal tides
}

\author{
J. Aguzzi ${ }^{1, *}$, C. Costa $^{2}$, Y. Furushima ${ }^{3}$, J. J. Chiesa ${ }^{4}$, J. B. Company ${ }^{1}$, P. Menesatti ${ }^{2}$, \\ R. Iwase ${ }^{3}$, Y. Fujiwara ${ }^{3}$ \\ ${ }^{1}$ Institut de Ciències del Mar (ICM-CSIC), Passeig Marítim de la Barceloneta 37-49, 08003 Barcelona, Spain \\ ${ }^{2}$ CRA-ING (Agricultural Engineering Research Unit of the Agriculture Research Council), Via della Pascolare 16, \\ 00016 Monterotondo (Roma), Italy \\ ${ }^{3}$ Japan Agency for Marine-Earth Science and Technology (JAMSTEC), 2-15 Natsushima-Cho, Yokosuka, \\ Kanagawa 237-0061, Japan \\ ${ }^{4}$ Laboratorio de Cronobiología, Departamento de Ciencia y Tecnología, Universidad Nacional de Quilmes-CONICET, \\ Roque Sáenz Peña 352, B1876BXD Bernal, Buenos Aires, Argentina
}

\begin{abstract}
Behavioral rhythms in marine organisms are generally studied in coastal areas in relation to day-night and tidal cycles. In contrast, the presence of these rhythms in demersal deep-sea fauna remains poorly characterized at present due to technological constraints on direct observation and sampling repeatability. In this study, our aim was to determine the presence of tidally synchronized behavioral rhythms of the demersal fauna at a hydrocarbon seep in Sagami Bay (1100 m depth; central Japan) using automated video-image analysis. Time series of visual counts were obtained for eelpouts (zoarcid fishes), red crabs Paralomis multispina, and snails Buccinum soyomaruae. Water pressure data were used as a marker of internal tidal action. By fitting 24-h and 12-h Fourier harmonics onto 24-h time series segments, a power content value was obtained as a marker of diurnal and semidiurnal fluctuations within the biological data sets. Rhythms were stronger in eelpouts and were weaker in red crabs and snails. Visual counts of eelpouts peaked during spring phases with an infradian periodicity of $13 \mathrm{~d}$. These results are discussed, taking into consideration that animal responses may be of a reactive type (i.e. exogenous) or may be controlled by a biological clock through putative hydrodynamic entrainment. Observed differences in the magnitudes of the rhythms were related to the different modes of species locomotion (i.e. swimming in eelpouts versus walking and crawling in red crabs and snails, respectively) in relation to seabed currents.
\end{abstract}

KEY WORDS: Deep-sea $\cdot$ Hydrocarbon seep $\cdot$ Sagami Bay $\cdot$ Diel rhythms $\cdot$ Internal tides $\cdot$ Automated video-image analysis $\cdot$ Zoarcid fishes $\cdot$ Eelpouts $\cdot$ Paralomis multispina $\cdot$ Buccinum soyomaruae

Resale or republication not permitted without written consent of the publisher

\section{INTRODUCTION}

Rhythms are present at all levels of biological organization, from the behaviors of populations and their constituent individual members down to the molecular functions of single cells (reviewed by Dunlap et al. 2004, Refinetti 2006). Studies of behavioral and physiological rhythms in marine species have generally been carried out in coastal areas in relation to day-night and tidal cycles (Naylor 2005). Only a few studies have dealt with these rhythms at deep-water continental margins and in the deep sea, which is one of the largest ecosystems on earth (Glover \& Smith 2003). On shelf and slope areas where light is still present, rhythms have been characterized with respect to daynight and seasonal changes (reviewed by Aguzzi \& Company 2010). Conversely, in the aphotic deep sea, behavioral rhythms, which are regulated by internal tides and inertial currents, are poorly understood (Wagner et al. 2007, Aguzzi et al. 2009d). For species at 
these depths, hydrodynamic changes may replace fluctuations in light intensity as the zeitgeber (i.e. the environmental synchronizer of rhythms), hence modulating the behavior of organisms in relation to displacement for feeding and also affecting other important life traits such as colonization and dispersal (reviewed by Levin et al. 2001, Kritzer \& Sale 2006).

The temporal functioning of an ecosystem depends on the sum of the biological rhythms of all of the species that constitute the community (Kornfeld-Schor \& Dayan 2003). In deep-water zones, the rhythmic displacements of animals in and out of sampling windows produce changes in measurements of the biomass and biodiversity of a given region (Aguzzi et al. 2003, 2008, Aguzzi \& Bahamon 2009, Coll et al. 2010). For example, the compositions of species in trawl hauls and the estimates of biodiversity that are derived from these species compositions can change within a given area depending on the time of the day or the season in which sampling occurs (Aguzzi et al. 2009a, Bahamon et al. 2009). Temporally scheduled trawling should be repeated in the same area so that variations in the species composition of the haul can be used as a proxy for behavioral modulation in the species in the sample (reviewed by Aguzzi \& Sardà 2008). However, trawling repeatability is generally constrained for both technical and economic reasons (Raffaelli et al. 2003). In this context, the pace of technological development in sampling and direct observation methods represents one of the major bottlenecks for behavioral studies in relation to habitat cycles in deep oceanic zones (Aguzzi et al. 2009c, 2010).

In the past 2 decades, the number of cabled observation stations with video recording equipment has increased (Benoit-Bird \& Au 2006). Unfortunately, the video footage that has been collected from these stations has generally been of short duration compared to what is required to produce a consistent behavioral time series analysis. The reason for this is the absence of proper automation of image analysis, which often obliges researchers to manually survey large quantities of images (Walther et al. 2004, Cline et al. 2007). In this study, we used an automated video-image analysis protocol that combined animal movement tracking and classification using multivariate morphometry (Aguzzi et al. 2009c) to search for possible tide-related behavioral rhythms in deep-sea species. We processed 2 mo of continuous footage showing the behavior of the demersal fauna of a geologically and ecologically important environment, the hydrocarbon seep of Sagami Bay (1100 m depth; central Japan). Time series based on visual counts of the most representative species in the footage were studied in relation to pressure variations at the seabed produced by changes in water depth at tidal pulls. Pressure variations were used as a marker of internal tide-associated bottom currents (Ohwaki et al. 1991), and this oceanographic parameter was also measured continuously during the same interval over which the video recording occurred.

\section{MATERIALS AND METHODS}

Video footage and the video-image analysis. Video footage (62 d from 17 April to 18 June 1999) was captured by a submarine infrared 3CCD video camera mounted on the cabled Real-Time Deep-Sea Floor Permanent Observatory (Iwase et al. 2003), which is a multisensory station located off of Hatsushima Island (Fig. 1; Sagami Bay, central Japan) in a hydrocarbon seep clam field (Calyptogena soyoae Okutani, 1957) at a depth of $1100 \mathrm{~m}$. The video camera acquired images continuously in time-lapse mode, capturing one frame every $5 \mathrm{~s}$, under a constant source of white illumination. Four white $250 \mathrm{~W}$ halogen lamps were always on during video recording operations.

Automated video-image analysis was performed according to the methods recently developed by Aguzzi et al. (2009c). A customized script was created in MATLAB 7.1 to recognize and then count eelpouts (Zoarcid fishes), red crabs Paralomis multispina (Benedict, 1894), and snails Buccinum soyomaruae Okutani, 1977. These were selected because they are the most representative fauna of the local hydrocarbon seep community (Fujikura et al. 2002).

Video originally stored on S-VHS tapes was pre-processed for digitization and consequent partitioning into frames at a rate equivalent to the frequency of video acquisition. Automated processing was based on motion detection of animals (i.e. tracking by means of image extraction) and recognition of animals (i.e. classification by profile identification). Motion detection identifies moving objects by following objects through consecutive frames (Lipton et al. 1998). The central area within the camera field was identified as a region of special interest, and the subtraction of consecutive frames took place within that area. Pixel differences indicated moving objects. Moving animals were discriminated from inanimate particulate matter (e.g. fouling), by filtering the extracted images based on size (pixel area) and color (pixel red/green/blue, RGB texture). The resulting animal profiles were classified as different species using the complex Fourier descriptors and supervised standard k-nearest neighbors morphometric analyses (Menesatti et al. 2009). The use of both of these techniques concurrently allowed the comparison of the profile of a newly tracked animal with images included in a reference library that was previously created by Aguzzi et al. (2009c). 
Biological and physical time series analysis. The temporal variation in visual counts for the selected taxa was considered to be a proxy for their behavioral rhythms at a population level. For each species, time series of visual counts taken at 5-s intervals were binned using a 10-min bin size. Tidally related variations in depth in Sagami Bay are linked to up- and down-sloping deep-sea-bottom tidal currents (Ohwaki et al. 1991). Oceanographic data pertaining to water depth were also gathered at 5-s intervals throughout the period of video recording using a hydrostatic sensor that was mounted on the cabled observatory. The resulting time series were then binned for each 10-min interval to allow for comparisons with the biological data sets. Unfortunately, due to the malfunction of the mooring array, data on the bottom current speed and direction were not retrieved.

The time series analysis was carried out using El Temps software (A. Diez-Noguera; University of Barcelona). Serial Fourier analysis was used to quantify the amplitude of fluctuation on diurnal and semidiurnal temporal scales in the data sets of visual counts for the 3 species (Aguzzi et al. 2005). Time series were partitioned into 24-h segments, and 2 harmonics, 24-h and $12-\mathrm{h}$, were modeled as being representative of the diurnal and semidiurnal tidal periodicity, respectively. Both harmonics were fitted separately to each time series segment to obtain a Power Content (PC) value as a percentage of the contribution of each harmonic to the total data set variance ( $\% \operatorname{Var}_{24}$ and $\left.\% \operatorname{Var}_{12}\right)$. PC

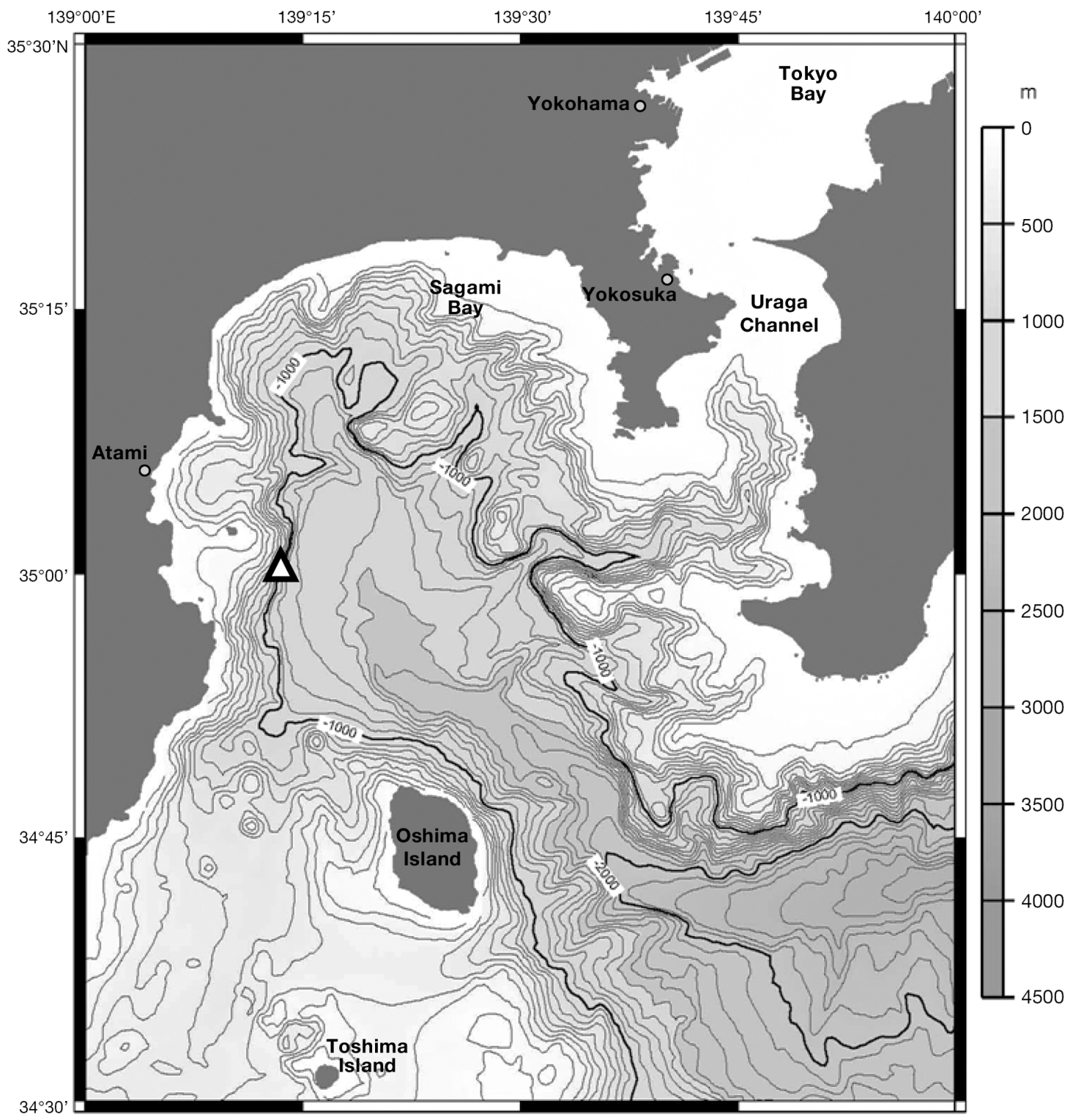

Fig. 1. Geographic and depth location (triangle) of the cabled observatory of Sagami Bay (central Japan) 
values were considered to be a measure of the strength of rhythms (Hsu 1973). For each selected taxa, \%Var time series containing 62 points were then obtained for both harmonics.

The occurrence of significant $(\mathrm{p}<0.05)$ differences in the $\% \operatorname{Var}_{24}$ and $\% \operatorname{Var}_{12}$ time series values among species was evaluated using a 2-way ANOVA as a measure of the differential strength in the rhythms. To do this, species and harmonics were considered as factors. Then, a post-hoc Fisher's test was conducted to detect significant $(p \leq 0.05)$ differences between harmonics and species.

$\% \operatorname{Var}_{24}$ and $\% \operatorname{Var}_{12}$ time series for all selected taxa were screened with the Lomb-Scargle periodogram analysis (Ruf 1999) at the range of 1 to $30 \mathrm{~d}$ to assess the occurrence of any significant $(p \leq 0.05)$ infradian periodicity (i.e. $>1$ d) corresponding to spring-neap tidal alternations. The periodogram routine calculates the spectral power, $\mathrm{P}$, for an increasing sequence of frequencies (in reciprocal units of the time array, T). The returned period values are associated with a spectral power.

A cross-correlation function was also calculated to measure the temporal agreement between the amplitude of the \%Var time series and bathymetric fluctuations. For this purpose, the \% Var time series were compared with water depth maxima and minima for each 24-h period throughout the testing period. The physical time series was lagged by $1 \mathrm{~d}$ against the \%Var time series for the 24-h and the 12-h harmonics to obtain the correlation value and its significance for lag $=0\left(\rho_{0}\right)$ (i.e. the contemporary series).

A waveform analysis was carried out on the time series of biological and oceanographic data in order to estimate the mean daily profile of rhythms fluctuations. Each data set was subdivided into 24 -h segments, and all of their constituting values were averaged through all of the subsets at corresponding timings (i.e. for each 10-min bin). The result was a waveform in the form of a consensus curve constructed using mean values that were represented along with their standard errors (SEM). A daily mean was estimated from each waveform profile in order to evaluate the temporal amplitude of the waveform peak (i.e. the phase). In order to do so, all waveform values were averaged, and the resulting mean was plotted as a line onto the plot. For a better visualization of the daily pattern of fluctuation, the waveform obtained from each time series was doubleplotted by repeating its 24 -h profile in a 48 -h format.

\section{RESULTS}

A total of 10808 visual counts were obtained for eelpouts (zoarcid fishes). The counts of red crabs Par- alomis multispina and snails Buccinum soyomaruae were 14441 and 18311, respectively. The range of fluctuation in the visual counts for these species during the 62-d study period was from a common minimum of 0 , when no individual was observed, to a maximum of 138, 91, and 98 for eelpouts, red crabs, and snails, respectively. Behavioral observations showed alternating moments of swimming activity and rest on the seabed for eelpouts. Red crabs exhibited phases of active zig-zag locomotion interspersed with phases of arrested motion. Snails exhibited linear trajectories of crawling motion.

Time series of visual counts for eelpouts, red crabs, and snails are presented in Fig. 2, along with the concomitant sea-level variations. The time series of bathymetric data indicated a fluctuation of $\sim 1.5 \mathrm{~cm}$, showing alternate phases of large and small deviations that were related to predicted spring and neap tides respectively. Visual counts for eelpouts increased during spring phases, and also between the first and second half of the observation period. No clearly defined fluctuation patterns were discernible for red crabs or snails.

Serial Fourier analysis outputs (Fig. 3) indicated the occurrence of differential strengths in the coupling of depth fluctuations with fluctuations in the visual count time series for eelpouts, red crabs, and snails. The 24 -h and 12-h \% Var time series for eelpouts showed peaks during spring tidal phases. For crabs, the agreement between the $\% \operatorname{Var}_{24}$ and $\% \operatorname{Var}_{12}$ time series and the bathymetric fluctuations was less pronounced. \%Var for both harmonics did not clearly peak during spring tidal phases. Likewise, no agreement between the time series and the bathymetric fluctuations was seen for snails. The $\% \operatorname{Var}_{24}$ and $\% \operatorname{Var}_{12}$ time series did not exhibit discernible fluctuations in relation to spring tidal phases.

The \%Var time series exhibited different average $( \pm$ $\mathrm{SD})$ values over the 62-d study; these average values are a measure of the differential strength of the tidal signal. For eelpouts, these percentages were $11.4 \%$ $( \pm 6.5)$ for the 24 -h harmonic and $10.4 \%( \pm 4.2)$ for the 12-h harmonic. In red crabs, these were $9.7 \%( \pm 4.6)$ for the 24 -h harmonic and $8.7 \%( \pm 4.5)$ for the 12 -h harmonic. In snails, the average variances were $11.3 \%$ $( \pm 4.0)$ for the 24 -h harmonic and $8.4 \%( \pm 3.8)$ for the 12 -h harmonic. The $\%$ Var values for eelpouts were significantly higher than those values reported for the other 2 species. A 2-way ANOVA detected the occurrence of significant $(p \leq 0.05)$ differences in the $\%$ Var between species $(p=0.0171)$ and harmonics $(p=$ 0.0008). The post-hoc Fisher's test (Table 1) revealed significant $(\mathrm{p} \leq 0.05)$ differences as follows: (i) eelpouts $\% \operatorname{Var}_{24}>$ red crabs $\% \operatorname{Var}_{24}$ and $\% \operatorname{Var}_{12}>$ snails $\% \operatorname{Var}_{12}$ (ii) eelpouts \% $\operatorname{Var}_{12}>$ red crabs \% $\operatorname{Var}_{12}$ i and finally, (iii) snails $\% \operatorname{Var}_{24}>$ red crabs $\% \operatorname{Var}_{12}>$ snails $\% \operatorname{Var}_{12}$. 
Periodogram analysis outputs for PC time series of data are reported in Fig. 4 as an indication of differential coupling among the visual count time series for the selected taxa and bathymetric fluctuations driven by the spring and neap tidal regime. For eelpouts, a significant 13-d infradian periodicity was detected for the PC time series of both harmonics using Lomb-Scargle periodogram analysis. This periodicity corresponded to that of the
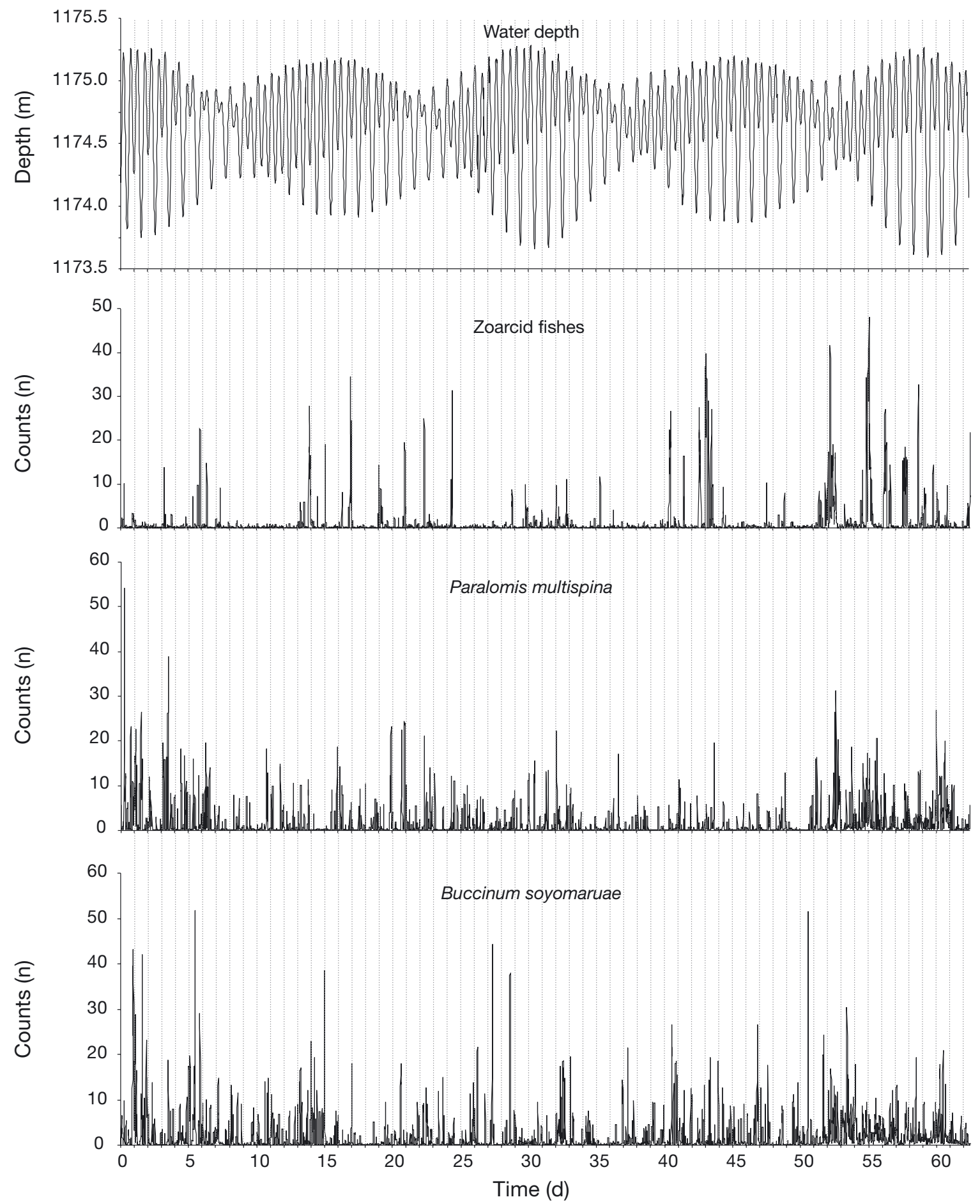

Fig. 2. Eelpouts (Zoarcid fishes), red crabs Paralomis multispina and snails Buccinum soyomaruae. Fluctuations in water depth showing spring and neap tides and time series of visual counts obtained by automated video-image analysis. Vertical thin lines define consecutive days and have been added to visually correlate physical and biological fluctuations 
bathymetric fluctuations, which also showed a significant 13-d peak in the periodogram plot. The output of the periodogram analysis for red crabs only showed a significant periodicity for the \% Var time series values for the 12-h harmonic. For snails, no infradian periodicity was detected by periodogram analysis.
The temporal relationship between fluctuations in the $\% \operatorname{Var}_{24}$ and $\% \operatorname{Var}_{12}$ time series and the effects of spring-neap tidal phases was statistically quantified using a cross-correlation test. In eelpouts, a significant crosscorrelation with the spring phase was found both for $\% \operatorname{Var}_{24}\left(\rho_{0}=0.30>0.25\right.$ for $\left.\mathrm{p}=0.05\right)$ and for $\% \operatorname{Var}_{12}$
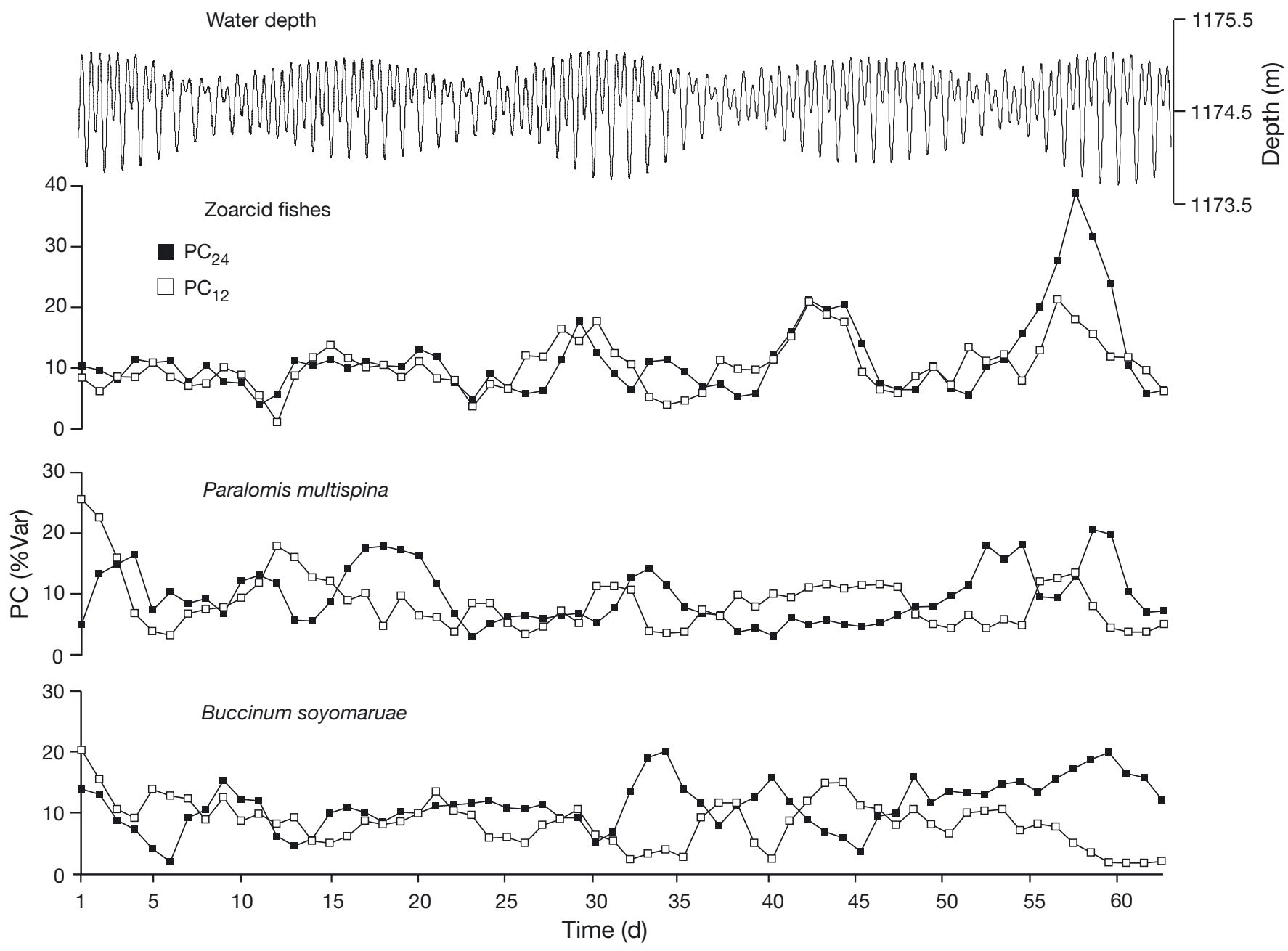

Fig. 3. Eelpouts (Zoarcid fishes), red crabs Paralomis multispina and snails Buccinum soyomaruae. Daily variations in water depth and serial Fourier analysis outputs showing the time series of Power Content (PC) values for both the 12-h and 24-h harmonics $\left(\% \operatorname{Var}_{24}\right.$ and $\left.\% \operatorname{Var}_{12}\right)$, as calculated by fitting these onto 24 -h visual count data sets

Table 1. Results of a post-hoc Fisher's test performed to detect significant differences among \% Var time series for 24-h and 12-h harmonics for eelpouts, red crabs and snails. Bold indicates the occurrence of significant comparisons $(p \leq 0.05)$

\begin{tabular}{|ccccccccc|}
\hline & Species & Harmonics & 1 & 2 & 3 & 4 & 5 \\
\hline 1 & Eelpouts & 24 & & 0.2096 & $\mathbf{0 . 0 4 0 7}$ & $\mathbf{0 . 0 0 1 3}$ & 0.9241 & $\mathbf{0 . 0 0 0 5}$ \\
2 & Eelpouts & 12 & 0.2096 & & 0.4256 & $\mathbf{0 . 0 4 8 2}$ & 0.2462 \\
3 & Red crabs & 24 & $\mathbf{0 . 0 4 0 7}$ & 0.4256 & & $\mathbf{0 . 0 2 3 8}$ \\
4 & Red crabs & 12 & $\mathbf{0 . 0 0 1 3}$ & 0.0482 & 0.2368 & & 0.0510 & 0.1420 \\
5 & Snails & 24 & 0.9241 & 0.2462 & 0.0510 & $\mathbf{0 . 0 0 1 8}$ & $\mathbf{0 . 0 0 1 8}$ & 0.7747 \\
6 & Snails & 12 & $\mathbf{0 . 0 0 0 5}$ & $\mathbf{0 . 0 2 3 8}$ & 0.1420 & 0.7747 & $\mathbf{0 . 0 0 0 7}$ \\
\hline
\end{tabular}



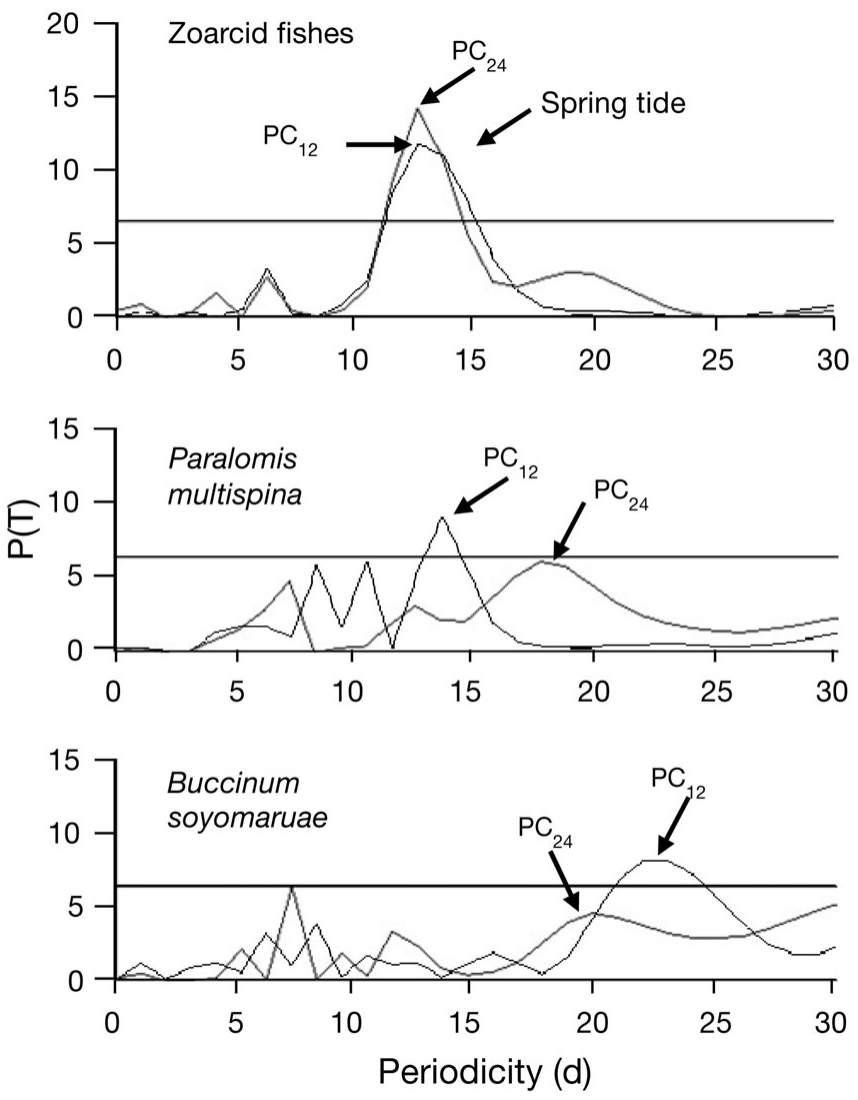

Fig. 4. Eelpouts (Zoarcid fishes), red crabs Paralomis multispina and snails Buccinum soyomaruae. Computed outputs of periodogram analysis for time of Power Content (PC) values. The periodogram analysis output for depth fluctuation data is shown in the Zoarcid periodogram plot. The continuous horizontal line within the periodogram plot represents the significance threshold $(\mathrm{p} \leq 0.05)$. Period values are associated with a spectral power $(\mathrm{P})$ as detected by screening time series for sequences of increasing duration, in units of time $(\mathrm{T})$.

$\left(\rho_{0}=0.29>0.25\right.$ for $\left.p=0.05\right)$, and the neap effect also showed a significant anti-correlation with $\% \operatorname{Var}_{24}\left(\rho_{0}=\right.$ $-0.27>0.25$ for $\mathrm{p}=0.05)$. In crabs, the cross-correlation was significant only for $\% \operatorname{Var}_{12}\left(\rho_{0}=0.30>0.25\right.$ for $\mathrm{p}=$ 0.05), and it was not significant for either harmonic in snails.

Waveform analysis outputs (Fig. 5) confirmed the differential strength reported in tidally oriented behavioral rhythms of the 3 studied taxa. The diel (i.e. 24-h) and tidal (i.e. 12-h) fluctuation patterns were stronger for zoarcid fishes than for red crabs and snails. In zoarcid fishes, that pattern was concomitant with the average bathymetric fluctuation as already indicated by the cross-correlation analysis (i.e. \% $\operatorname{Var}_{24}$ and $\operatorname{Var}_{12}$ versus bathymetric data). Waveform peaks for zoarcid fishes had large SEM since the average of the visual count data was computed using days for which the tidal peaks were of different amplitudes (see Fig. 2).

\section{DISCUSSION}

In this study, we analyzed the occurrence of internaltide-related activity rhythms in different vertebrate and invertebrate species in a deep-sea hydrocarbon seep community. Using an automated video-image analysis protocol that was developed recently (Aguzzi et al. 2009c), we assessed the occurrence of these rhythms using visual counts of zoarcid fishes (eelpouts), red crabs Paralomis multispina and snails Buccinum soyomaruae.

The time series analysis for eelpouts demonstrated the presence of a strong semilunar periodicity on the timescale of spring-neap tidal fluctuations ( 13 $\mathrm{d}$; see Fig. 3A). This was interpreted as a proxy for rhythmic increases and decreases in the swimming activity of the local zoarcid population in relation to alternately increasing and decreasing cycles of water flow. Previous studies have already demonstrated that eelpouts can adjust their behavior to match conditions of differing current strengths and directions (reviewed by Uiblein et al. 2002, Trenkel et al. 2004, Lorance \& Trenkel 2006). Cummings and Morgan (2001) also described a strengthening of swimming rhythms during spring tidal phases for Zoarcids in the laboratory. The comparison of our results with those previously published (Kimura et al. 1990, Shinohara \& Sakurai 2006) indicates the presence of a common tidal regulation of behavior in different species within the eelpout morphotype.

Data on the speed and direction of currents at the seabed were not available for comparison with biological time series due to the malfunctioning of the mooring array. These oceanographic data are necessary to determine the existence of direct cause-effect relationships between behavioral patterns and changes in water motion (Aguzzi et al. 2010). In Sagami Bay, bathymetric excursions have been associated with internal tides, which mix the water column from the surface down to the deep-sea bottom (Kitade et al. 2004), generating up and down currents along the slope of $\sim 20 \mathrm{~cm} \mathrm{~s}^{-1}$ (Ohwaki et al. 1991). The alongslope motion of these currents was assessed by underwater photography, which identified stream-oriented sediment marks and characteristic megabenthos positioning (reviewed by Okada \& Otha 1993).

Reported differential strengths in tidally oriented rhythms for the 3 studied species may be explained by their different mode of active displacement, which in turn accounts for a markedly different substrate interaction (reviewed by Aguzzi \& Company 2010). Eelpouts are benthic boundary layer swimmers that are potentially more vulnerable to changes in water flow than walking crabs and crawling snails (Eguchi et al. 1997). A similarity in the mode of locomotion in phylogenetically different marine species can drive the morphological and metabolic convergence of taxa (re- 


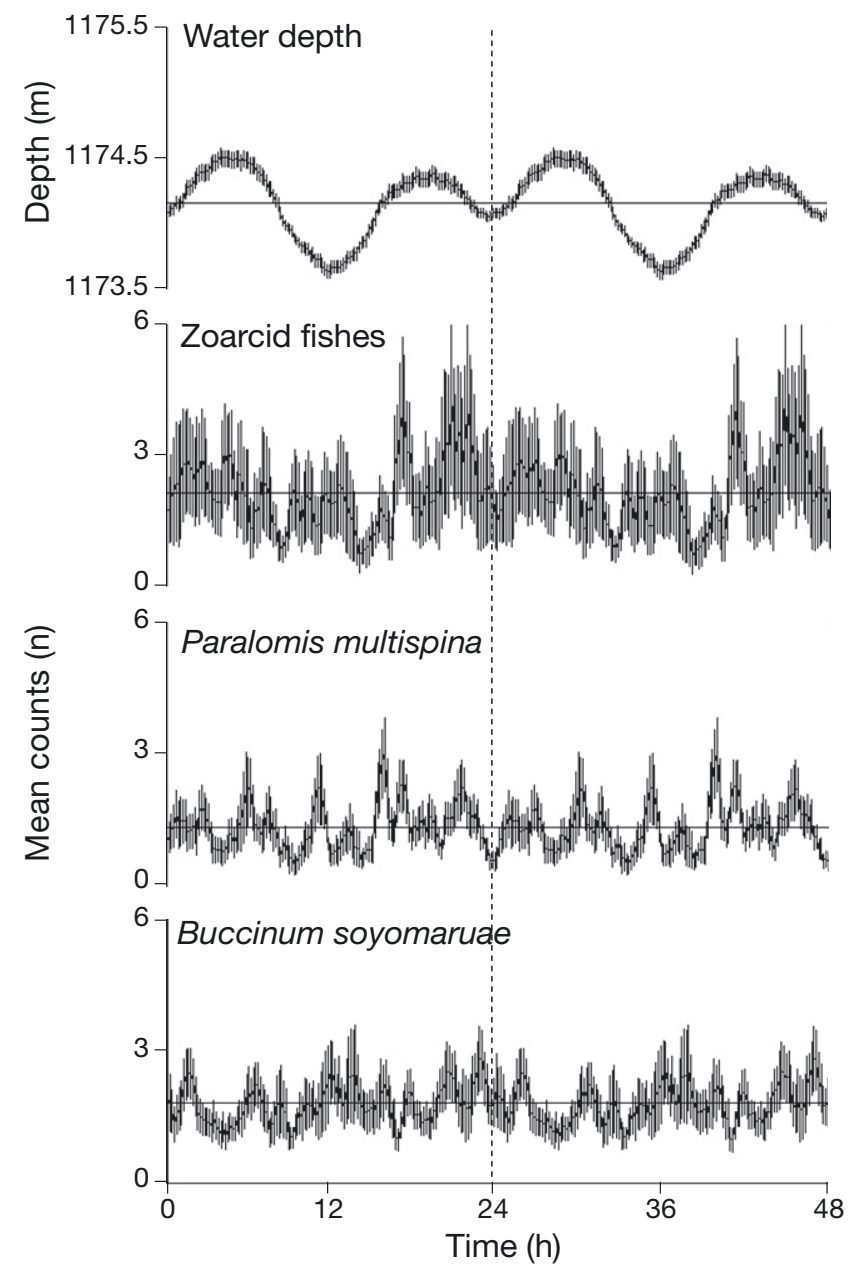

Fig. 5. Eelpouts (Zoarcid fishes), red crabs Paralomis multispina and snails Buccinum soyomaruae. Double-plotted waveforms for mean visual counts and fluctuation in water depth (black lines: mean values; gray shading around these: SD). Horizontal lines depict the daily mean as threshold defining the temporal amplitude of fluctuation peaks (i.e. the phases). The vertical dashed line indicates the repetition of the 24 -h standard cycle (i.e. the double plotted asset)

viewed by Hicks 1988, Childress 1995, Company \& Sardà 1998, Pulcini et al. 2008, Aguzzi et al. 2009b). That convergence may also occur at the level of behavioral rhythms and their regulation.

The behavioral rhythms that we report here may be the product of an exogenous reactive response, or alternatively, these may be the result of anticipation; therefore, they may be fully endogenously generated via biological clock control (reviewed by Naylor 2005). Small changes in hydrostatic pressure reinforce the tidal rhythm in coastal fishes (Gibson 1984) and crustaceans (Akiyama 2004). Additionally, the modulation of behavior in response to tidal hydrodynamics was previously observed in fishes performing diel vertical migrations (Michalsen et al. 1996) and in coastal crabs (Thurman 2004; Brown et al. 2010). The activity cycles reported herein were not observed under laboratory constant conditions, and therefore, the presence of a biological clock sustaining an endogenous rhythm cannot be proven.

Any discussion on the exogenous or endogenous nature of tidally oriented rhythms should be carried out by considering 2 important aspects of the deep sea: the highly variable character of current flow regimes (reviewed by Garrett 2003, Simmons 2008) and the food-depletion (Childress 1995). Most of the effect of currents on the behavior of deep-sea animals has been related to feeding (Lampitt et al. 1983, Priede et al. 1994, Jones et al. 1998, Levin et al. 2001). An exogenous response to food odor from one current direction may evoke a swimming response. In the deep sea, scavengers can locate corpses over great distances by olfaction of organic chemicals dissolved in water plumes (Tamburri \& Barry 1999, Bailey et al. 2007). Food can also be involved in the endogenous response because its temporally scheduled administration reinforces endogenous behavioral rhythms in fishes and decapods. Food pulses set the phase of functioning of light-independent peripheral oscillators such as the liver and the hepatopancreas (in fishes and decapods, respectively; Fernandéz de Miguel \& Aréchiga 1994, Reebs 2002). In this scenario, directional food odors within tidal wave fronts may reinforce the hydrodynamic entrainment of behaviors in deep-sea fauna. Food perception, localization (by behavioral activation), and consequent food retrieval and ingestion may all represent important aspects of the behavioral repertoire that interact in tidal entrainment (Aguzzi et al. 2009d). However, to our knowledge, no study to date has demonstrated that food can entrain a tidal rhythm.

Our deep-sea observations were carried out under bright lights, creating an unnatural environmental that may affect behavioral tests by damaging the optic apparatus of local fauna (Widder et al. 2005) and by favoring an escaping response (Gaten et al. 1999). Additionally, the circadian rhythmicity of individuals can be altered by constant light-on conditions in the laboratory (Dunlap et al. 2004), but that phenomenon has not yet been tested in deep-sea animals. However, our recording conditions did not impair the detection of clear swimming rhythms for fishes, as have been reported in other behavioral studies where light attraction responses have also been observed (e.g. Trenkel et al. 2004; Lorance \& Trenkel 2006). In this work, we detected a tidal-related rhythm in fishes, which usually had trajectories avoiding the central lighted seabed area (Aguzzi et al. 2009c). Conversely, the other 2 invertebrate species had trajectories that fully encompassed the light field, but their tidally oriented rhythms are comparatively less clear. Crabs and snails may be 
less affected by direct illumination exposure than fishes (Watanabe 2002). The possibility that these animals may have rhythms that might be disturbed by the artificial lighting should be further investigated.

Our study indicates that video-imaging techniques can be successfully used for long-term and remote monitoring of deep-sea rhythms when a suitable level of automation in digital footage processing is achieved. The population approach can be successful for the determination of species responses to cyclically fluctuating habitat parameters, when the observed rhythmic pattern is considered to be an average property of the animals within the group (Simonetta et al. 2009). Video-imaging technology will contribute to our understanding of the temporal functioning of these ecosystems on diel and seasonal timescales based on the integrated analysis of activity rhythms of species in relation to recurrent habitat events such as internal tidal fluctuations.

Acknowledgements. The authors acknowledge Dr. H. de la Iglesia (Univ. of Washington, USA), Dr. P. Puig and Dr E. Ramirez-Llorda (both at the ICM-CSIC), for their help during the manuscript elaboration. The present work was developed within the framework of 2 research projects funded by the MICINN (NORIT, CTM/2005/02034 and PROMETEO, CTM 2007-66316-C02-02/MAR) and the Italian Ministry of Agricultural, Food and Forestry Politics (HighVision, DM 19177/ 7303/08). Jacopo Aguzzi is a Postdoctoral Fellow of the 'Ramon y Cajal' Program (Ministerio de Ciencia e Innovación, MICINN).

\section{LITERATURE CITED}

Aguzzi J, Bahamon N (2009) Modelled day-night biases in decapod assessment by bottom trawling survey. Fish Res 100:274-280

Aguzzi J, Company JB (2010) Chronobiology of deep water continental margin decapods. Adv Mar Biol Ann Rev 58: $157-226$

Aguzzi J, Sardà F (2008) A history of recent advancements on Nephrops norvegicus behavioural and physiological rhythms. Rev Fish Biol Fish 18:235-248

Aguzzi J, Company JB, Abelló P (2003) Circadian oxygen consumption patterns in continental slope Nephrops norvegicus (Decapoda: Nephropidae) in the western Mediterranean. J Crustac Biol 23:749-757

Aguzzi J, Chiesa J, Abelló P, Diez-Noguera A (2005) Temporal modification in cardiac rhythmicity of Nephrops norvegicus (Crustacea: Decapoda) in relation to trawl capture stress. Sci Mar 69:369-374

Aguzzi J, Sarriá D, García JA, Del Rio J, Sardà, F, Manuel A (2008) A new tracking system for the measurement of diel locomotor rhythms in the Norway lobster, Nephrops norvegicus (L.). J Neurosci Met 173:215-224

Aguzzi J, Bhamon N, Marotta L (2009a) Modulation of activity rhythms in continental margin decapods by light availability and predatory behaviour of Nephrops norvegicus. PSZNI: Mar Ecol 30:366-375

Aguzzi J, Costa C, Antonucci F, Company JB, Menesatti P, Sardá F (2009b) Influence of rhythmic behaviour in the morphology of decapod natantia. Biol J Linn Soc 96: $517-532$

Aguzzi J, Costa C, Menesatti P, Fujwara Y, Iwase R, RamirezLlorda E (2009c) A novel morphometry-based protocol of automated video-image analysis for species recognition and activity rhythms monitoring in deep-sea fauna. Sensors 9:8438-8455

Aguzzi J, Puig P, Company JB (2009d) Hydrodynamic, nonphotic modulation of biorhythms in the Norway lobster, Nephrops norvegicus (L.). Deep-Sea Res I 56:366-373

Aguzzi J, Company JB, Costa C, Menesatti P and others (2010) Activity rhythms in the deep-sea: a chronobiological approach. Front Biosci 16:131-150

Akiyama T (2004) Entrainment of the circatidal swimming activity rhythm in the cumacean Dimorphostylis asiatica (Crustacea) to 12.5-hour hydrostatic pressure cycles. Zoolog Sci 21:29-38

Bahamon N, Sardà F, Aguzzi J (2009) Fuzzy diel pattern in commercial catchability of deep-water continental margin species. ICES J Mar Sci 66:2211-2218

Bailey DM, Wagner HJ, Jamieson AJ, Ross MF, Priede IG (2007) A taste of the deep-sea: the roles of gustatory and tactile searching behaviour in the grenadier fish Coryphaenoides armatus. Deep-Sea Res I 54:99-108

> Benoit-Bird KJ, Au WW (2006) Extreme diel horizontal migrations by a tropical near shore resident micronekton community. Mar Ecol Prog Ser 319:1-14

Brown H, Benfield MC, Keenan SF, Powers SP (2010) Movement patterns and home ranges of a pelagic carangid fish, Caranx crysos, around a petroleum platform complex. Mar Ecol Prog Ser 403:205-218

> Childress JJ (1995) Do animals present biochemical adaptations to depths? Trends Ecol Evol 10:30-36

Cline DE, Edgington DR, Mariette J (2007) An automated visual event detection system for cabled observatory video. MTS/IEEE Oceans 2007 Conf Proc. IEEE Press, Vancouver

Coll M, Piroddi C, Steenbeek J, Kaschner K and others (2010) Biodiversity of the Mediterranean Sea: status, patterns and threats. PLoS I 5:e11842

Company JB, Sardà F (1998) Metabolic rates and energy content of deep-sea benthic decapod crustaceans in the western Mediterranean Sea. Deep-Sea Res I 45:1861-1880

Cummings SM, Morgan E (2001) Time-keeping system of the eelpout, Zoarces vivparus. Chronobiol Int 18:27-46

Dunlap JC, Loros JJ, DeCursey P (2004) Chronobiology: biological timekeeping. Sinauer, Sunderland, MA

- Eguchi E, Dezawa M, Meyer-Rochow B (1997) Compound eye in Paralomis multispina Benedict, an anomuran half-crab from 1200 m depth (Crustacea; Decapoda; anomura). Biol Bull 192:300-308

> Fernandéz de Miguel F, Aréchiga H (1994) Circadian locomotor activity and its entrainment by food in the crayfish Procambarus clarkii. J Exp Biol 190:9-21

Fujikura K, Hashimoto J, Okutani T (2002) Estimated population densities of megafauna in two chemosynthesis-based communities: a hydrocarbon seep in Sagami Bay and a hydrothermal vent in the Okinawa Trough. Benthos Res 57:21-30

Garrett C (2003) Internal tides and ocean mixing. Science 301:1858-1859

Gaten E, Herring PJ, Shelton PMJ (1999) Irreversible eye damage in bresiliid vent shrimps caused by submersible lights. In: Schram FR, von Vaupel Klein JC (eds) Crustaceans and the biodiversity crisis. Brill, Leiden, p 871-877

Gibson RN (1984) Hydrostatic pressure and rhythmic behaviour of intertidal marine fishes. Trans Am Fish Soc 113: $479-483$ 
Glover AG, Smith CR (2003) The deep-sea floor ecosystem: current status and prospects of anthropogenic change by the year 2025. Environ Conserv 30:219-241

Hicks GRF (1988) Evolutionary implications of swimming behaviour in meiobenthic copepods. Hydrobiol 167-168: 497-504

Hsu HP (1973) Análisis de Fourier. Fondo Educativo Interamericano, Mexico

Iwase R, Asakawa K, Mikada H, Goto T and others (2003). Off Hatsushima island laboratory in Sagami Bay: multidisciplinary long-term observation at cold seepage site with underwater mateable connectors for future use. Proc 3rd Int Workshop on Scientific Use of Submarine Cables and Related Technologies. IEEE Press; Vancouver, p 31-34

Jones EG, Collins MA, Bagley PM, Addison S, Priede IG (1998) The fate of cetacean carcasses in the deep sea: observations on consumption rates and succession of scavenging species in the abyssal north-east Atlantic Ocean. Proc Biol Sci 265:1119-1127

Kimura S, Khono Y, Tsukamoto Y, Okyiama M (1990) Record of the parabrotulid fish Parabrotula plagiophthalma from Japan. Jpn J Ichthyol 37:318-320

Kitade Y, Matsuyama M, Ishimaru T, Saino T, Nakamura T, Ishii M (2004) Vertical structure and intermittency of internal tides observed at the center of Sagami Bay. Oceanog Japan 13:461-474

Kritzer JP, Sale PF (2006) Marine metapopulations. Elsevier Academic Press, San Diego, CA

Kornfeld-Schor N, Dayan T (2003) Partitioning of time as an ecological resource. Ann Rev Ecol Syst 34:153-181

Lampitt RS, Merret NR, Thurston MH (1983) Interrelation of necrophagous amphipods, a fish predator and tidal currents in the deep-sea. Mar Biol 74:73-78

Levin LA, Etter RJ, Rex MA, Gooday AJ and others (2001) Environmental influences on regional deep-sea species diversity. Annu Rev Ecol Syst 32:51-93

Lipton AJ, Fujiyoshi H, Patil RS (1998) Moving target classification and tracking from real-time video. Proc 4 th Workshop on Applications of Computer Vision (WACV'98). IEEE Press, Vancouver, p 8-14

> Lorance P, Trenkel VM (2006) Variability in natural behaviour, and observed reactions to an ROV, by mid-slope fish species. J Exp Mar Biol Ecol 332:106-119

Menesatti P, Aguzzi J, Costa C, García JA, Sardà F (2009) Video-image analysis for microcosm experiments on activity rhythms with multiple individuals of Norway lobster, Nephrops norvegicus (L.) J Neurosci Met 184:161-168

> Michalsen K, Godø OR, Fernö A (1996) Diel variation in the catchability of gadoids and its influence on the reliability of abundance indices. ICES J Mar Sci 53:389-395

Naylor E (2005) Chronobiology: implications for marine resources exploitation and management. Sci Mar 69:157-167

Ohwaki A, Matsuyama M, Iwata S (1991) Evidence for predominance of internal tidal currents in Sagami and Suruga bays. J Oceanogr 47:194-206

Okada H, Ohta S (1993) Photographic evidence of variable bottom-current activity in the Suruga and Sagami Bays, central Japan. Sed Geol 82:221-237

Editorial responsibility: Steven Morgan,

Bodega Bay, California, USA
Priede IG, Bagley PM, Smith A, Creasey S, Merrett NR (1994) Scavenging deep demersal fishes of the Porcupine Seabight, north-east Atlantic: observations by baited camera, trap and trawl. J Mar Biol Assoc UK 74:481-498

Pulcini D, Costa C, Aguzzi J, Cataudella S (2008) Light and shape: a contribution to demonstrate morphological differences in diurnal and nocturnal teleosts. J Morphol 269: 375-385

Raffaelli D, Bell E, Weithoff G, Matsumoto A and others (2003) The ups and downs of benthic ecology: considerations of scale, heterogeneity and surveillance for benthic-pelagic coupling. J Exp Mar Biol Ecol 285-286:191-203

Reebs SG (2002) Plasticity of diel and circadian activity rhythms in fishes. Rev Fish Biol Fish 12:349-371

Refinetti R (2006) Circadian physiology. Taylor \& Francis Group, Boca Raton, FL

Ruf T (1999) The Lomb-Scargle periodogram in biological rhythm research: analysis of incomplete and unequally spaced time-series. Biol Rhythm Res 30:178-201

Shinohara G, Sakurai H (2006) Ericandersonia sagamia, a new genus and species of deep-water eelpouts (Perciformes: Zoarcidae) from Japan. Ichthyol Res 53:172-178

Simmons HL (2008) Spectral modification and geographic redistribution of the semi-diurnal internal tide. Ocean Model 21:126-138

Simonetta SH, Migliori LM, Romanowski A, Golombek DA (2009) Timing of locomotor activity circadian rhythms in Caenorhabditis elegans. PLoS ONE 4:e7571

Tamburri MN, Barry JP (1999) Adaptations for scavenging by three diverse bathyal species, Eptatretus stouti, Neptunea amianta and Orchomene obtusus. Deep-Sea Res I 46: 2079-2093

> Thurman CL (2004) Unraveling the ecological significance of endogenous rhythms in intertidal crabs. Biol Rhythm Res 35:43-67

> Trenkel VM, Lorance P, Mahevas S (2004) Do visual transects provide true population density estimates for deepwater fish? ICES J Mar Sci 61:1050-1056

> Uiblein F, Pascal L, Latrouite D (2002) Variation in locomotion behaviour in northern cutthroat eel (Synaphobranchus kaupi) on the Bay of Biscay continental slope. Deep-Sea Res I 49:1689-1703

> Wagner HJ, Kemp K, Mattheus U, Priede IG (2007) Rhythms at the bottom of the deep-sea: cyclic current flow changes and melatonin patterns in two species of demersal fish. Deep-Sea Res I 54:1944-1956

Walther D, Edgington DR, Koch C (2004) Detection and tracking of objects in underwater video. Proc 2004 IEEE Comp Soc Conf on Computer Vision and Pattern Recognition (CVPR'04), Washington, DC, Vol 1. IEEE Press, Vancouver, 544-549

Watanabe T (2002) Method to estimate the population density of the snow crab Chionoecetes opilio using a deep-sea video monitoring system on a towed sledge. Jpn Agric Res Q 36:51-57

Widder EA, Robison BH, Reisenbichler KR, Haddock SHD (2005) Using red light for in situ observations of deep-sea fishes. Deep-Sea Res I 52:2077-2085

Submitted: May 14, 2010; Accepted: September 20, 2010 Proofs received from author(s): November 8, 2010 